\title{
ANALISIS FAKTOR PENENTU ADOPSI CLOUD COMPUTING PADA LAYANAN KESEHATAN
}

\author{
Mohammad Bhanu Setyawan \\ Universitas Muhammadiyah Ponorogo \\ J1. Budi Utomo No.10, Ponorogo \\ mohammad.setyawan@gmail.com
}

\begin{abstract}
Abstrak
Artikel ini bertujuan untuk mengetahui faktorfaktor penentu adopsi cloud computing di rumah sakit Muhammadiyah di Jawa Timur dengan menggunakan Technology Acceptance Model (TAM). Sampel yang digunakan dalam penelitian ini adalah 29 sampel rumah sakit dengan alat analisis yang digunakan untuk membangun model adalah: perceived ease of use, perceived usefulness, security effectiveness, reliabilty, needs, cost effectiveness, top management support, complexity, behavioral intention to use dan actual usage. Evaluasi goodness of fit dan resampling bootstraping digunakan untuk menganalisis kelayakan model. Evaluasi goodness of fit model struktural diukur menggunakan nilai predictive-relevance diperoleh nilai sebesar $=0,95$ yang artinya model memiliki nilai prediktif yang sangat baik. Hasil olah data diperoleh dengan menggunakan resampling bootstraping dengan menghitung hubungan antar variabel memiliki nilai thitung yang lebih besar $=2.01$ dalam adopsi cloud computing di rumah sakit Muhammadiyah di Jawa Timur. Hasil analisis data diperoleh enam variable mempunyai pengaruh positif dan signifikan dalam adopsi cloud computing, yaitu: Perceived usefulness, Perceived ease of use, complexity, needs, top management support dan behavioral intention to use. Selain itu ada tiga variabel secara positif namun tidak signifikan dalam adopsi cloud computing, yaitu: Security effectiveness, reliability dan cost effectiveness
\end{abstract}

Kata kunci: cloud computing, needs, technology acceptance model, top management support, behavioral intention to use, partial leastsquare

\begin{abstract}
This article aims to determine the factors influencing the adoption of cloud computing in the hospital by using Technology Acceptance Model (TAM). The sample used in this study is 29 samples hospital with an analysis tool used to build the model are: perceived ease of use, perceived usefulness, security effectiveness, reliabilty, needs, cost effectiveness, top management support, complexity, behavioral intention to use and actual usage. Evaluation of the goodness of fit and bootstrapping resampling is used to analyze the feasibility of this model. Evaluation of the goodness of fit of the structural model is measured using a predictive valuerelevance obtained a value of $=0.95$ which means that the model has predictive value was very good. Results if the data is obtained using bootstrapping resampling by calculating the relationship between variables have the value $t$ count bigger $=2.01$ in the adoption of cloud computing in the Muhammadiyah hospital in East Java. Results of data analysis obtained six variables have positive and significant influence in the adoption of cloud computing, namely: Perceived usefulness, Perceived ease of use, complexity, needs, top management support and behavioral intention to use. In addition there are three of these variables is positive but not significant in the adoption of cloud computing, namely: Security effectiveness, reliability and cost effectiveness
\end{abstract}

Keywords: cloud computing, needs, technology acceptance model, top management support, behavioral intention to use, partial leastsquare 


\section{Pendahuluan}

Cloud computing merupakan teknologi informasi yang saat ini mulai populer. Kedepannya akan semakin banyak pebisnis dan konsumen yang menggunakan layanan cloud computing, dan sebagian besar dari mereka akan memilih provider yang mampu mengakomodir kebutuhan end-to-end, dari perangkat hingga infrastruktur. Perubahan paradigma ini menyebabkan banyak organisasi yang bermigrasi dan mengadopsi teknologi cloud computing (Laksman, 2013) Cloud computing merupakan fenomena baru, sehingga penelitian tentang topik ini masih terbatas, seperti penelitian mengenai cloud computing architecture Rochwerger, et al.,(2009), biaya dan keuntungan cloud computing (Assuncao, Costanzo, \& Buyya, 2009), aplikasi potensial (Liu \& Orban, 2008), faktor-faktor yang mempengaruhi adopsi cloud computing oleh perusahaan (Low, Chen, $\& \mathrm{Wu}, 2011)$.

Salah satu fokus penelitian pengembangan di dunia adalah di bidang teknologi informasi kesehatan, salah satunya adalah jaringan rumah sakit Muhmmadiyah Jawa Timur (JRSM). JRSM adalah pelayanan kesehatan industri yang menyediakan teknologi informasi berbasis sistem cloud computing. JRSM mampu menghubungkan, memonitoring, mengendalikan untuk pengambilan keputusan dari setiap jaringan unit pelayanan kesehatan milik Muhammadiyah.

Menentukan dan membuat keputusan mengadopsi teknologi cloud computing untuk suatu organisasi bukanlah pekerjaan mudah dan sering kali berspekulasi tentang teknologi ini kedepannya apakah akan digunakan atau tidak, karena apabila tidak mempertimbangkan faktor-faktor apa saja yang mempengaruhi dalam mengadopsi cloud computing, akan memperbesar kesalahan dalam pengambilan keputusan (Rahimli, 2013).

TAM (Technology Acceptance Model) adalah salah satu model yang paling sering digunakan pada penelitian adopsi di bidang sistem informasi. Penelitian-penelitian yang ada memvalidasi kebenaran TAM dalam menguji berbagai macam penggunaan teknologi informasi pada berbagai jenis instansi dan perusahaan dan diakui oleh para peneliti di dunia (Farahwahida, 2011).

Mendapatkan factor penentu yang mempengaruhi adopsi sebuah teknologi cloud computing bisa membantu para manager dan staf TI rumah sakit Muhammadiyah di Jawa Timur dalam mengevaluasi dan meningkatkan sistem TI di tempat mereka bekerja. Penelitian ini mencoba memberikan informasi yang sesuai bagi organisasi yang ingin membuat keputusan untuk mengadopsi cloud computing dan agar mereka tahu mana faktor-faktor yang penting bagi rumah sakit Muhammadiyah dalam mengadopsi cloud computing

\section{KAJIAN LITERATUR}

\section{II.1 Konsep Dasar Cloud Computing}

Cloud computing sebagai sebuah model yang memungkinkan adanya penggunaan sumber daya secara bersama-sama dan mudah, menyediakan jaringan akses dimana-mana, dapat dikonfigurasi, dan layanan yang digunakan sesuai keperluan (Mell \& Grance, 2011).

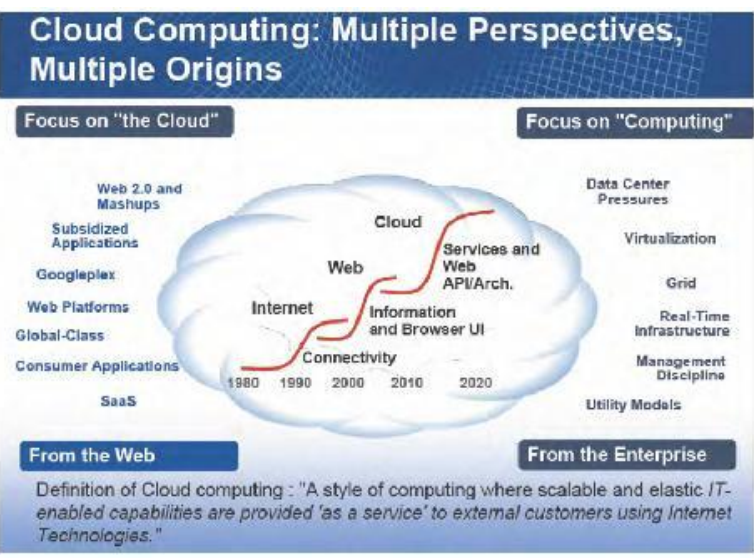

Gambar 1. Paradigma cloud computing ditinjau dari berbagai perspektif (Shimba F, 2010)

Cloud computing memiliki sejumlah karakteristik yang membedakannya dengan komputasi lainnya. Terdapat lima buah karakteristik khusus yang dimiliki oleh cloud computing yaitu: on demand service, broad network access, Resources pooling, rapid elasticity dan measured service (Shimba F, 2010).

Terdapat empat model layanan cloud computing yang bisa dipilih sesuai dengan kebutuhan antara lain: SaaS (software as service), PaaS (Platform a service), IaaS (infrastructure as service) dan HaaS (hardware as service) (Laksman, 2013).

Model deployment dari cloud computing dibagi menjadi empat model. Kempat model deployment tersebut mencakup private cloud, public cloud, 
community cloud dan hybrid cloud (Mell \& Grance, 2011)

\section{II.2 Technology Acceptance Model (TAM)}

Teori Technology Acceptance Model (TAM) adalah adaptasi dari Theory of Reasoned Action (TRA) yang dikembangkan oleh Davis (1986) untuk konteks penerimaan (acceptance) pengguna terhadap Sistem Informasi. Tujuan dari pengembangan TAM ini adalah memberikan penjelasan terhadap faktorfaktor penentu penerimaan sistem informasi yang lebih umum sifatnya, sehingga dapat menjelaskan perilaku pengguna dari berbagai ragam teknologi komputasi dan pengguna. Sehingga dengan demikian dapat menjadi dasar untuk mengetahui dampak faktor eksternal (external variables) pada keyakinan (beliefs), sikap (attitude) dan niat (intentions) dalam penggunaan (actual usage) suatu system informasi

\section{Cost Effectiveness}

Cost Effectiveness adalah hubungan antara biaya yang dikeluarkan dengan hasil yang menguntungkan (Rahimli, 2013)

\section{Needs}

Beberapa perusahaan memerlukan teknologi cloud computing. Cloud computing memberikan berbagai macam layanan untuk kebutuhan akan sumber daya komputasi (Biddick, 2008)

\section{Reliability}

Reliabilty berarti kualitasnya dapat dihandalkan dengan downtime yang minimum. Hal ini berguna bagi pengguna atau organisasi yang bergantung pada kehandalan komputasi, respon yang cepat, keamanan informasi dan penyimpanan data ke komputer yang bebasis aplikasi (Rahimli, 2013).]

\section{Security Effectiveness}

Security effectiveness pada cloud computing dapat didefinisikan sebagai probabilitas subjektif dimana konsumen percaya bahwa informasi mereka tidak akan dilihat, disimpan, atau dimanipulasi ke pihak lain selama proses transmisi data dan disimpan secara konsisten (Lule, 2013).

\section{Top Management Support}

Top Management Support mengacu pada dukungan dari para pimpinan organisasi tentang sifat dan pemanfaatan teknologi cloud computing. Dukungan top management support sangat penting untuk menciptakan iklim yang kondusif dan menyediakan sumber daya yang memadai untuk adopsi teknologi baru (Mansour, 2013)

\section{Metode Perancangan dan Analisis}

\section{III.1 Metode Penelitian}

Langkah-langkah penelitian dimulai dengan identifikasi masalah dan perencanaan penelitian, kemudian tahap pengumpulan data dilanjutkan pengolahan data dengan menggunakan teknik analisis Partial Least Square 2.0 (PLS), hasilnya kemudian di lakukan analisis dan interpretasi data untuk ditarik sebuah kesimpulan dan rekomendasi/saran.

\section{III.2 Model Penelitian}

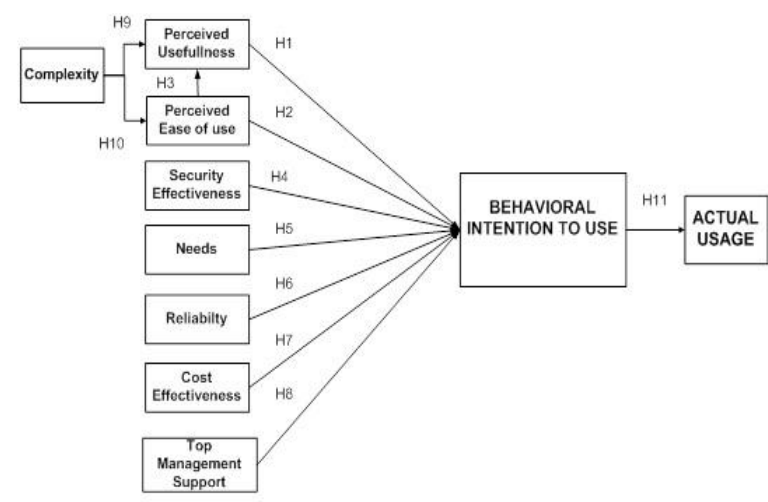

\section{Gambar 2. Model Penelitian}

Gambar 2 adalah model penelitian yang dikembangkan untuk menganalisis variabel yang mempengaruhi adopsi cloud computing di Rumah Sakit Muhammadiyah, penulis mengusulkan model penelitian TAM yang terintegrasi merujuk pada model yang dikembangkan oleh Davis (1986) dan Kwang-Kyu Seo (Seo, 2013), Sedangkan cost effectiveness, security effectiveness, needs, reliability, top management support ditambahkan dan diidentifikasi dengan mempertimbangkan karakteristik dan pentingnya penggunaan layanan cloud computing

\section{III.3 Hasil dan Pembahasan}

\section{III.3.1. Langkah-langkah Penelitian}

Penelitian ini merupakan jenis penelitian kuantitatif dengan langkah-langkah penelitian sebagai berikut. Studi pustaka dan literature terkait adopsi cloud computing, Partial Least Square (PLS) dan penelitian terdahulu yang memiliki kemiripan topik 
dengan penelitian ini. Perencanaan penelitian ini terdiri dari, tahap pengumpulan data, tahap pengolahan data, analisis dan interpretasi data dan penarikan kesimpulan dan saran.

Tahap pengumpulan data ini, meliputi empat hal, yaitu: penentuan indikator, pembuatan kuisioner, dan penyebaran kuisioner. Data yang akan diambil dalam penelitian ini adalah data primer, dimana data secara langsung dari obyek penelitian. Populasi yang akan diteliti dalam penelitian ini sebanyak 25 obyek rumah sakit yang tergabung dalam yayasan Muhammadiyah Jawa Timur dan sudah menggunakan cloud computing. Pada penelitian ini semua obyek akan diambil datanya. Dalam peneltian ini menggunakan skala likert, dengan bobot nilai 1,2,3,4,5. Teknik pengukuran data yang digunakan adalah skala sikap.

Tahap pengolahan data menggunakan pengujian uji reliabilitas dan validitas untuk melihat kehandalan kuesioner yang telah dibuat menggunakan teknik analisis metode Partial Least Square (PLS) dalam paket software SmartPLS versi 2.0. Tahapan analisis teridiri dari: merancang model struktural (inner model), merancang model pengukuran (outer model), mengkonstruksi Diagram jalur (path Diagram), konversi diagram jalur ke dalam sistem persamaan, pendugaan parameter (estimasi: koef. jalur, loading dan weight), evaluasi goodness of fit, dan pengujian hipotesis (resampling bootstraping). Analisis hasil pengolahan PLS merupakan proses interpretasi data hasil SmartPLS dilengkapi dengan analisis langkahlangkah perbaikan mengacu pada hasil.

Interpretasi hasil pengujian dari output hasil analisis, sehingga diperoleh gambaran tentang hasil pengukuran. Kesimpulan dan saran, simpulan dari hasil pengujian dan rekomendasi untuk penelitian lanjutan, saran yang mungkin disampaikan pada organisasi yang bergerak di bidang kesehatan.

\section{III.3.2. Model Pengukuran (Outer Model)}

Outer model atau model pengukuran mendefinisikan bagaimana setiap blok indikator berhubungan dengan variabel latennya (Ghozali, 2008). Ada tiga kriteria untuk menilai outer model, yaitu convergent validity, composite reliability, dan discriminant validity.

\section{III.3.3. Convergent Validity}

Semua indikator yang digunakan pada penelitian ini memiliki loading factor lebih besar dari 0,5 dan signifikan ( $\mathrm{t}$ hitung $>\mathrm{t}$ tabel), sehingga tidak ada indikator yang dibuang. $\mathrm{t}$ tabel $=2.01$ dapat dilihat di Tabel 1

Tabel 1. Outer Loading setiap indikator

\begin{tabular}{lcc}
\hline \hline \multicolumn{1}{c}{ Indikator } & $\begin{array}{c}\text { Original } \\
\text { Sample }\end{array}$ & $\begin{array}{c}\text { T Statistics } \\
\text { (|O/STERR|) }\end{array}$ \\
\hline \hline AU1 <- Actual Usage & 0.852514 & \\
AU2 <- Actual Usage & 0.666545 & 26.488575 \\
AU3 <- Actual Usage & 0.664322 & 9.734350 \\
BI1 <- BI & 0.867842 & 38.270108 \\
BI2 <- BI & 0.890285 & 51.107975 \\
BI3 <- BI & 0.888219 & 43.086289 \\
CE1 <- Cost & 0.755958 & 5.935273 \\
CE2 <- Cost & 0.885325 & 18.868133 \\
CE3 <- Cost & 0.820953 & 10.236266 \\
CO1<- Complexity & 0.967109 & 89.539947 \\
CO2<- Complexity & 0.973977 & 169.313567 \\
NE1 <- Needs & 0.908005 & 47.494885 \\
NE2 <- Needs & 0.911427 & 58.878500 \\
NE3 <- Needs & 0.928060 & 56.792351 \\
PE1 <- PEOU & 0.897717 & 66.409513 \\
PE2 <- PEOU & 0.883039 & 45.394641 \\
PE3 <- PEOU & 0.790287 & 20.989010 \\
PU1 <- PU & 0.939863 & 59.737790 \\
PU2 <- PU & 0.919105 & 48.694716 \\
PU3 <- PU & 0.837472 & 28.284620 \\
RE1 <- Reliability & 0.852358 & 14.666149 \\
RE2 <- Reliability & 0.873646 & 15.028861 \\
RE3 <- Reliability & 0.909944 & 8.361211 \\
SE1 <- Security & 0.925753 & 60.144661 \\
SE2 <- Security & 0.888652 & 31.489327 \\
SE3 <- Security & 0.699470 & 9.131747 \\
TM1 <- Top & 0.843020 & 32.596746 \\
TM2 <- Top & 0.934309 & 65.315472 \\
TM3 <- Top & 0.846833 & 24.461186 \\
\hline & & \\
\hline
\end{tabular}

III.3.4. Discriminant Validity.

Nilai akar kuadrat dari AVE setiap konstruk harus lebih besar daripada korelasi antara konstruk dengan konstruk lainnya dalam model. Selain itu nilai AVE masing-masing konstruk harus lebih besar dari 0,5 sehingga dapat kita simpulkan bahwa model memiliki discriminant validity yang cukup dapat dilihat di Tabel 2 
Tabel 2. AVE dan akar AVE

\begin{tabular}{lcc}
\hline \hline Variabel & AVE & Akar AVE \\
\hline \hline Actual Usage & 0.593967 & 0.770693 \\
Behavioral Intention to & 0.778230 & 0.882173 \\
Use & 0.941965 & 0.970549 \\
Complexity & 0.687887 & 0.82939 \\
Cost Effectiveness & 0.838822 & 0.915872 \\
Needs & 0.807743 & 0.898745 \\
Perceived Usefullness & 0.691674 & 0.831669 \\
Perceived ease of use & 0.772590 & 0.878971 \\
Reliability & 0.711993 & 0.843797 \\
Security Effectiveness & & 0.878978 \\
Top Management & 0.772602 & \\
Support & & \\
\hline \hline
\end{tabular}

\section{Composite Reliabilty}

Semua variabel yang digunakan pada penelitian ini memiliki composite reliability dan Cronbachs Alpha lebih besar dari 0,7. hal ini menunjukkan bahwa semua variabel pada penelitian ini memiliki reliabilitas yang baik, dapat dilihat pada Tabel 3 .

Tabel 3. Composite Reliability

\begin{tabular}{lcc}
\hline \hline Variabel & $\begin{array}{c}\text { Composite } \\
\text { Reliability }\end{array}$ & $\begin{array}{c}\text { Cronbachs } \\
\text { Alpha }\end{array}$ \\
\hline \hline Actual Usage & 0.878472 & 0.829247 \\
Behavioral Intention to & 0.913241 & 0.857473 \\
Use & 0.970115 & 0.938593 \\
Complexity & 0.897824 & 0.855795 \\
Cost Effectiveness & 0.939801 & 0.904097 \\
Needs & 0.943741 & 0.920003 \\
Perceived Usefullness & 0.899207 & 0.849668 \\
Perceived ease of use & 0.910591 & 0.853604 \\
Reliability & 0.879723 & 0.799288 \\
Security Effectiveness & 0.931348 & 0.901211 \\
Top Management & & \\
Support &
\end{tabular}

\section{III.4 Model Struktural (Inner Model)}

Pengujian atau penilaian terhadap model struktural dilakukan dengan melihat nilai R-square untuk konstruk dependen, dan uji t serta signifikansi dari koefisien parameter jalur strukturalnya yang didapat lewat prosedur bootsraping
Tabel 4. R-Square

\begin{tabular}{ll}
\hline & R Square \\
\hline \hline Actual Usage & 0.472138 \\
Behavioral Intention to Use & 0.825775 \\
Perceived Usefullness & 0.514731 \\
Perceived ease of use & 0.131198 \\
\hline \hline & $\mathrm{Q}^{2}=1-\left(1-\mathrm{R}_{1}^{2}\right)\left(1-\mathrm{R}_{2}^{2}\right) \ldots\left(1-\mathrm{R}_{\mathrm{p}}\right)$
\end{tabular}

Diperoleh nilai predictive-relevance sebesar $\mathrm{Q}^{2}=$ 0,95949 atau 95,94\%. Artinya model dapat menjelaskan fenomena adopsi cloud computing dikaitkan dengan beberapa variabel sebesar $95,94 \%$. Oleh karena itu model dapat dikatakan sangat baik, atau model memiliki nilai prediktif yang sangat baik. Pada akhirnya model dapat digunakan untuk pengujian hipotesis

\section{III.5 Analisis Hasil}

Pengujian dilakukan dengan menggunakan metode resampling Bootstrap yang dikembangkan oleh Geisser \& Stone. Statistik uji yang digunakan adalah uji t. Apabila t hitung yang diperoleh untuk masingmasing hubungan variabel memiliki nilai $t$ hitung yang lebih besar dibandingkan dengan $t$ tabel sebesar 2.01 maka hubungan itu signifikan. Berdasarkan koefisien pengaruh pada tabel 5 dan gambar 3, maka dapat dianalisis hal-hal sebagai berikut :

A. Berdasarkan tabel 5 dan gambar 3, hasil analisis menunjukkan bahwa koefisien jalur pengaruh langsung perceived ease of use terhadap behavioral intention to use nilai 0,258 pada $\mathrm{t}$ statistic 2,806 . Koefisien bertanda positif dapat diartikan bahwa hubungan antara perceived ease of use dan behavioral intention to use adalah searah, nilai t-statistik 2,806 lebih dari nilai ttabel yaitu 2,01 maka hubungan antar variabel signifikan. Artinya semakin tinggi perceived ease of use maka semakin besar tingkat behavioral intention to use cloud computing di lingkungan rumah sakit Muhammadiyah Jawa Timur

B. Berdasarkan tabel 5 dan gambar 3 , hasil analisis menunjukkan bahwa koefisien jalur pengaruh langsung perceived ease of use terhadap perceived usefullness diperoleh nilai 0,588 pada t-statistic 5,550. Koefisien bertanda positif dapat diartikan bahwa hubungan antara perceived ease of use dan perceived usefullness adalah searah. 
Nilai t-statistik 5.550 lebih dari nilai t-tabel yaitu 2,01 maka hubungan antar variabel signifikan.

Tabel 5. Koefisien Jalur

\begin{tabular}{cccc}
\hline $\begin{array}{l}\text { Hub.Antar } \\
\text { Varibel }\end{array}$ & $\begin{array}{c}\text { Path } \\
\text { Coefficient }\end{array}$ & $\begin{array}{c}\text { T } \\
\text { Statistics }\end{array}$ & Keterangan \\
\hline \hline BU -> AU & 0.687123 & 16.861108 & Signifikan \\
CO -> PU & 0.248685 & 2.624072 & Signifikan \\
COy -> PEOU & 0.362212 & 3.648845 & Signifikan \\
CE -> BI & 0.010096 & 0.217061 & Nonsignifikan \\
NE -> BI & 0.274987 & 2.836863 & Signifikan \\
PU -> BI & 0.178004 & 2.030025 & Signifikan \\
PEOU -> BI & 0.258158 & 2.806271 & Signifikan \\
PEOU -> PU & 0.588894 & 5.550466 & Signifikan \\
RE -> BI & 0.002013 & 0.039641 & Nonsignifikan \\
SE -> BI & 0.029099 & 0.493527 & Nonsignifikan \\
TM -> BI & 0.282396 & 3.588807 & Signifikan \\
\hline \hline
\end{tabular}

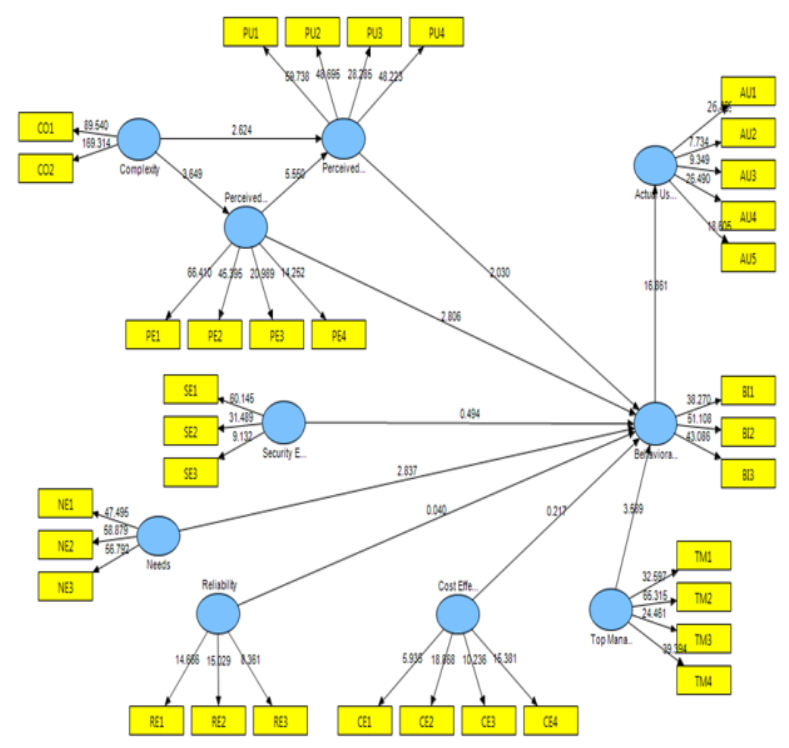

Gambar 3. Koefisien jalur

C. Berdasarkan tabel 5 dan gambar 3 menunjukkan bahwa koefisien jalur pengaruh langsung security effectiveness terhadap behavioral intention to use diperoleh nilai 0,0290 pada tstatistic 0,493 . Koefisien bertanda positif dapat diartikan bahwa hubungan antara perceived ease of use dan perceived usefullness adalah searah, nilai t-statistik 0,493 kurang dari nilai t-tabel yaitu 2,01 maka hubungan antar variabel tidak signifikan. Artinya semakin tinggi security effectiveness maka belum tentu semakin besar tingkat behavioral intention to use cloud computing.

D. Berdasarkan gambar 3 dan tabel 5 , hasil analisis menunjukkan bahwa koefisien jalur pengaruh langsung needs terhadap behavioral intention to use diperoleh nilai 0,274 pada t-statistic 2,836. Koefisien bertanda positif dapat diartikan bahwa hubungan antara needs dan behavioral intention to use adalah searah, nilai tstatistik 2.836 lebih dari nilai t-tabel yaitu 2,01 maka hubungan antar variabel signifikan. Artinya semakin tinggi needs maka semakin besar tingkat behavioral intention to use.

E. Berdasarkan gambar 3 dan tabel 5, hasil analisis menunjukkan bahwa koefisien jalur pengaruh langsung reliabilty terhadap behavioral intention to use diperoleh nilai 0,002 pada t-statistic 0,039 . Koefisien bertanda positif dapat diartikan bahwa hubungan antara reliabilty dan behavioral intention to use adalah searah dan t-statitstik kurang dari 2,01 yang artinya tidak signifikan. Artinya semakin tinggi reliabilty maka belum tentu semakin besar tingkat behavioral intention to use cloud computing.

F. Berdasarkan gambar 3 dan tabel 5, hasil analisis menunjukkan bahwa koefisien jalur pengaruh langsung cost effectiveness terhadap behavioral intention to use diperoleh nilai 0,01 pada tstatistic 0,217. Koefisien bertanda positif dapat diartikan bahwa hubungan antara cost effectiveness dan behavioral intention to use adalah searah dan t-statitstik kurang dari 2,01 yang artinya tidak signifikan. artinya semakin tinggi cost effectiveness maka belum tentu semakin besar tingkat behavioral intention to use (niat untuk menggunakan) cloud computing.

G. Berdasarkan gambar 3 dan tabel 5 , hasil analisis menunjukkan bahwa koefisien jalur pengaruh langsung top management support terhadap behavioral intention to use diperoleh nilai 0,282 pada t-statistic 3,588. Koefisien bertanda positif dapat diartikan bahwa hubungan antara reliabilty dan behavioral intention to use adalah 
searah, nilai t-statistik lebih dari 3,588 maka hubungan antar variabel signifikan. Artinya semakin tinggi top management support maka semakin besar tingkat behavioral intention to use (niat untuk menggunakan) cloud computing.

H. Berdasarkan gambar 3 dan tabel 5, hasil analisis menunjukkan bahwa koefisien jalur pengaruh langsung complexity terhadap perceived usefullness diperoleh nilai 0,248 pada t-statistic 2,624. Koefisien bertanda positif bertanda positif dapat diartikan bahwa hubungan antara complexity dan perceived usefullness adalah searah, dan nilai statistik lebih dari t-tabel 2.01 dapat diartikan signifikan.

I. Berdasarkan gambar 3 dan tabel 5, hasil analisis menunjukkan bahwa koefisien jalur pengaruh langsung complexity terhadap perceived ease of use diperoleh nilai 0,362 pada t-statistic 3,648. Koefisien bertanda positif dan nilai t-statistik lebih dari nila t-tabel 2,01, artinya hasil penelitian ini menunjukkan bahwa semakin mudah tingkat complexity (kerumitan) suatu teknologi cloud computing mempengaruhi perceived ease of use teknologi cloud computing.

J. Berdasarkan gambar 3 dan tabel 5, hasil analisis menunjukkan bahwa koefisien jalur pengaruh langsung behavioral intention to use terhadap actual usage diperoleh nilai 0,687 pada $\mathrm{t}-$ statistik 16,86. Koefisien bertanda positif dan nilai t-statistik lebih dari t-tabel 2,01 maka hubungan antar variable positif dan signifikan. Artinya semakin tinggi behavioral intetion to use maka semakin besar pula tingkat actual usage dalam adopsi cloud computing.

\section{KESIMPULAN DAN SARAN}

Berdasarkan hasil analisis faktor-faktor yang mempengaruhi adopsi cloud commputing di rumah sakit Muhammadiyah Jawa Timur, diperoleh kesimpulan bahwa, terdapat delapan variable pendukung yang positif signifikan dan hanya tiga yang positif dan tidak siginifikan.

Faktor-faktor penting dan signifkan yang perlu diketahui dalam adopsi cloud computing di rumah sakit Muhammadiyah di wilayah Jawa Timur, antara lain: perceived usefulness, perceived ease of use, complexity, needs, top management support dan behavioral intention to use

Sedangkan faktor-faktor yang tidak signifikan dalam adopsi cloud computing di rumah sakit Muhammadiyah antara lain: cost effectiveness reliabilty dan security effectiveness

\section{REFERENSI}

Prasad, Laksman, \& Bapuji, 2013. Cloud Computing: Research Issues and Implications. International Journal of Cloud Computing and Sevices Sciense.

Rahimli, A. (2013). Factor Infulencing Organization Adoption Decisision of Cloud Computing. International Journal of Cloud Computing and Services Science.

Mohd, Farahwahida, Faufzi Ahmad, Norsila Samsudin, \& Suhizaz Sudin. 2011. Extending the Technology Acceptance Model to Account for Social Influence, Trust and Integration for Pervasive Computing Environment: A Case Study in University Industry. American Journal of Economics and Business Administration, 3(3), pp: 552-559.

Mell, P., \& Grance, T. (2011). THE NIST definition of Cloud Computing. National Institute of Standards and Technology.

Biddick, M. (2008). A Walk in the Clouds. Information Week Analytic Reports. Manhassett, NY: United Bussines Media Limited.

I. Lule, T. O., \& Waema, T. M. (2013). International Journal of Computing and ICT Research. Vol. 6 no.3.

Mansour, A. J. (2013). The Adoption of Cloud Computing Technology in Higher Education Institutions: Concerns and Challenges. Gaza: Islamic University of Gaza.

Seo, K.-K. (2013). An Explorative Model For B2B Cloud Services Adoption in Korea Focusing on IaaS Adoption. International Journal of Smart Home.

Ghozali, I. (2008). Structural Equation Modeling Metode Alternatif dengan Partial Least Square. Semarang: Badan Penerbit Universitas Diponegoro 